SHORT REPORT

\title{
Total time in English accident and emergency departments is related to bed occupancy
}

\author{
M W Cooke, S Wilson, J Halsall, A Roalfe
}

Emerg Med J 2004;21:575-576. doi: 10.1136/emj.2004.015081

S imulation modelling has suggested high bed occupancy in hospitals is associated with a greater risk of prolonged waits for admission in the accident and emergency (A\&E) department. ${ }^{1}$ The NHS Plan ${ }^{2}$ has introduced two standards for waits in A\&E. Firstly, the wait for admission from the time of a decision to admit (trolley wait); which is the wait that appears to be related to average bed occupancy within acute trusts. ${ }^{1}$ This is logical, as one would expect admissions to have to wait if beds are not readily available at all times. The second standard in the NHS Plan relating to $A \& E$ is the total time in A\&E measured from the arrival of the patient to their discharge from hospital or admission to a ward, this applies to all patients whether they are admitted or not. Therefore the vast majority will be patients who are discharged home. It would be expected that most of these patients would not be affected by the average bed occupancy in the trust unless the backlog of patients awaiting admission cause processes in the $A \& E$ department to slow down for the whole range of patients being seen.

The objective of this study was to discover if total time spent in A\&E departments is related to a trust's bed occupancy.

\section{METHODS}

Data on bed occupancy and percentage of patients spending over four hours in A\&E from arrival to admission or discharge are now routinely collected by the Department of Health for every acute trust in England. Data from 4 March to 17 March 2002 were analysed. Definitions of bed occupancy and total time are as defined in Department of Health guidance. ${ }^{3}$ It should be noted that bed occupancy is calculated from beds occupied at midnight compared with the hospitals total acute bed stock, including specialist beds. The association between percentage waiting time over four hours and bed occupancy at hospital level was assessed using weighted linear regression analysis, the normality assumption being confirmed by residual plots. ${ }^{4}$ This method accounts for the varying number of patients seen in A\&E at each hospital during the study period.

\section{RESULTS}

There are 176 NHS trusts in England with A\&E departments. Figures for total time in A\&E were obtained for 174 of these trusts. The other two sites were excluded as they only submitted percentages and no raw data. Bed occupancy figures were not available for 27 (15.3\%); analyses were based on the 147 hospitals with complete data.

A scattergram of the proportion of A\&E attendees waiting more than four hours against bed occupancy rates is given in figure 1 . The equation from the regression modelling was \% waiting over four hours $=-42.3 \quad(\mathrm{SE}=15.6)+0.8$ $(\mathrm{SE}=0.2)$ bed occupancy $\left(r^{2}=0.11 ; \mathrm{p}<0.0001\right)$.

\section{DISCUSSION}

This study shows that waits over four hours are correlated with the average bed occupancy in acute trusts. This has not been shown previously in the UK. It does not show a causal relation between the two.

Bed occupancy rates were not available for $15 \%$ of the population and these hospitals had to be excluded from the analysis. If either bed occupancy rates or the proportion of patients waiting more than four hours, in these hospitals, were not similar to that of those with complete data this may have affected the analysis. Data for bed occupancy and waiting times were obtained from routine reporting mechanisms (SitRep data) and have not been separately validated.

Bed occupancy levels above a safe threshold are associated with delays in admission via A\&E, which may divert resources away from other processes in the A\&E department. Non-availability of cubicles because they are occupied by patients waiting for admission may contribute to this problem. It has been proposed that streaming of minor injuries can decrease waiting times. ${ }^{5}$ In this system some cubicles are devoted to the care of minor injury cases. It would be expected that this system of "streaming" should mean there is little relation between bed occupancy and wait of non-admitted patients in the emergency department. If streaming is effective it would therefore be expected that the relation shown in this study should disappear as A\&E departments adopt this new method of working.

Equally if bed occupancy rates can be reduced below a threshold, it should be possible to decrease the proportion of

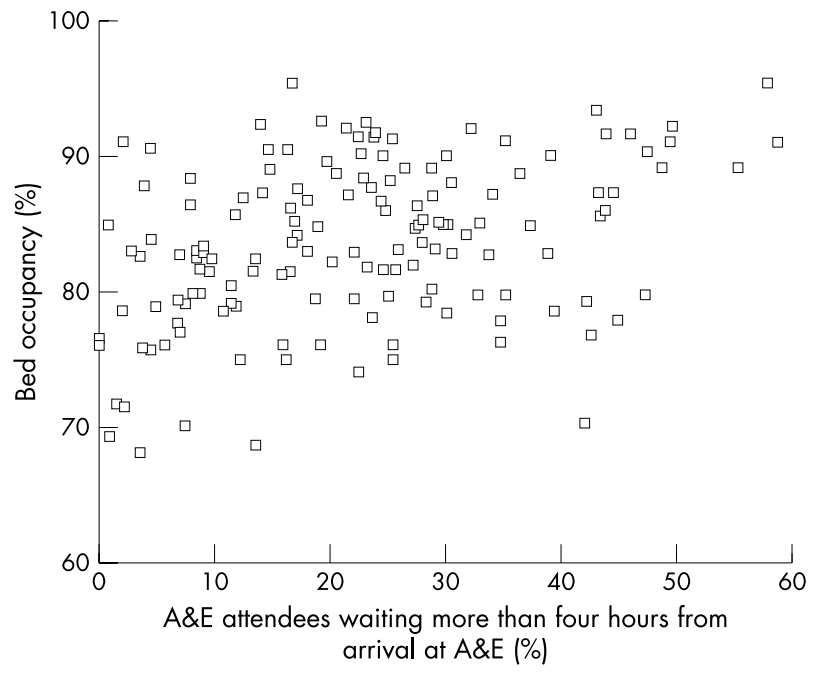

Figure 1 Scattergram of the proportion of A\&E attendees waiting more than four hours against bed occupancy. 
patients spending excessively long times, over four hours, within an A\&E department.

Further study of outliers in the distribution (for example, those with high bed occupancy but low total waits) may help to understand the reasons for and potential solutions of long waits in A\&E departments.

\section{CONTRIBUTORS}

MC had the original idea for the study, coordinated the analysis, and wrote the first draft of the paper. AR undertook the analysis of the data. JH collated the data. All four authors were involved in the writing of the paper. MC is the guarantor of the paper.

\section{Authors' affiliations}

M W Cooke, Emergency Medicine Research Group, Centre for Primary Health Care Studies, University of Warwick, Coventry, UK

S Wilson, A Roalfe, Department of Primary Care and General Practice, Division of Primary Care Public and occupational Health, University of Birmingham, UK

J Halsall, Department of Health, UK
Funding: Sue Wilson is supported by a Department of Health National Primary Care Career Scientist Award. Matthew Cooke is partly funded by the Department of Health.

Conflicts of interest: none declared.

Correspondence to: Dr M W Cooke, Emergency Medicine Research Group, Centre for Primary Health Care Studies, University of Warwick, Coventry, UK; m.w.cooke@warwick.ac.uk

Accepted for publication 28 May 2004

\section{REFERENCES}

1 Bagust A, Place M, Posnett JW. Dynamics of bed use in accommodating emergency admissions: stochastic simulation model. BMJ 1999;319:155-8. 2 Department of Health. The NHS Plan. London: Department of Health, 2000.

3 Department of Health. National situation reporting guidance. London: Department of Health, 2003.

4 Brown H, Prescott R. Applied mixed models in medicine. Chichester: Wiley, 1999.

5 Cooke MW, Wilson S, Pearson S. The effect of a separate stream for minor injuries on accident and emergency department waiting times. Emerg Med J 2002;19:28-30. 